\title{
Stool-Based Tests for Colorectal Cancer Screening: Performance Benchmarks Lead to High Expected Efficacy
}

\author{
Derek W. Ebner ${ }^{1}$ - John B. Kisiel ${ }^{1}$ (D) \\ Published online: 3 June 2020 \\ (C) The Author(s) 2020
}

\begin{abstract}
Purpose of Review Participation goals for colorectal cancer (CRC) screening in the USA have not been met. Non-invasive screening strategies may improve CRC screening participation. We highlight recent literature on stool-based screening performance and expectations for emerging non-invasive screening tests.

Recent Findings Stool-based CRC screening detects screen-relevant colorectal neoplasia and outperforms a currently available plasma assay. Though modestly sensitive for CRC, adherence to annual fecal immunochemical testing (FIT) is sub-optimal. Multi-target stool DNA (MT-sDNA) has greater adherence, superior sensitivity for screen-relevant lesions (including those in the proximal colon and sessile serrated architecture), and equivalent specificity to FIT over a 3-year period.

Summary Stool-based CRC screening tests are anticipated to reduce the incidence and mortality of CRC through detection of early-stage cancers and high-risk polyps. These endpoints in performance will need to be met by emerging blood sample-based tests in order have meaningful impact in clinical practice.
\end{abstract}

Keywords Colonic neoplasms/prevention - Fecal immunochemical test · Occult blood/methods · Multi-target stool DNA test . Liquid biopsy

$\begin{array}{ll}\text { Abbreviations } \\ \text { CRC } & \text { Colorectal cancer } \\ \text { CI } & \text { Confidence interval } \\ \text { FIT } & \text { Fecal immunochemical test } \\ \text { gFOBT } & \text { Guaiac-based fecal occult blood testing } \\ \text { MT-sDNA } & \text { Multi-target stool DNA } \\ \text { SEPT9 } & \text { Methylated SEPTIN9 } \\ \text { USPSTF } & \text { United States Preventive Services Task Force }\end{array}$

\section{Introduction}

In the USA, the death rate from colorectal cancer (CRC) has declined by $54 \%$ since 1970; ample evidence suggests that organized screening has played a major role in this considerable achievement [1-3]. Despite this progress, over 100,000

This article is part of the Topical Collection on GI Oncology

John B. Kisiel

Kisiel.john@mayo.edu

1 Division of Gastroenterology and Hepatology, Mayo Clinic, Rochester, MN, USA new cases of colon cancer and roughly 53,000 related deaths will occur this year in the USA, where CRC is the second leading cause of cancer-related death in men and women combined [1]. Globally, CRC is the second leading cause of cancer-related death and the incidence of CRC is increasing, particularly in countries with rising rates of saturated fat intake and/or smoking [4]. To prevent CRC, stool-based screening with a fecal immunochemical test (FIT) is most commonly used worldwide [5]; screening colonoscopy is used mostly in Germany and the USA.

Unlike a non-invasive screen, structural examinations (colonoscopy and flexible sigmoidoscopy) have the capacity to perform polypectomy; these enable removal of precursor lesions and lower the incidence and mortality of CRC [6]. For example, in a prospective randomized control study, those offered a one-time screening by flexible sigmoidoscopy had a decreased incidence and mortality of CRC by $33 \%$ and $43 \%$, respectively; this benefit with flexible sigmoidoscopy is mostly confined to the left colon [7, 8], where fewer than half of incident cases may occur [9]. In observational studies, colonoscopy also favorably reduces the incidence $(-56 \%)$ and mortality $(-68 \%)$ of CRC; however, this benefit was significantly greater in the left colon than the right [8]. 
Despite the reductions in $\mathrm{CRC}$ incidence and mortality from screening, adherence to $\mathrm{CRC}$ screening recommendations remains poor. It is estimated that nearly $1 / 3$ of eligible adults go unscreened for CRC [10••]. While absence of insurance or a regular health care provider are major barriers [11], adherence to structural screening tests is sub-optimal among those with access to care due to required time off of work, cost of structural screening, scheduling of the exam, bowel preparation, and fear of procedural pain/risks $[12,13]$. Noninvasive tests may be an attractive option for those who find these features of colonoscopy prohibitive. Controlled trial data suggest that when patients are offered a choice between structural (colonoscopy) and non-invasive screening (FIT), adherence rates are significantly higher than when referred for screening colonoscopy as the only modality [14].

When assessing the benefits of structural versus noninvasive screening for $\mathrm{CRC}$, it is important to recall that detection of curable-stage cancers will potentially lower CRC mortality; only tests that can detect precursors (and result in their ultimate removal) will lower CRC incidence. For example, annual guaiac-based fecal occult blood testing (gFOBT) has been shown in randomized controlled trials to lower the mortality from CRC by $14 \%$ over a 10-year period, compared with no screening but does not reduce CRC incidence [15, 16]. In contrast, newer generation occult blood testing by FIT detects early-stage cancer and some screen-relevant precancers, including advanced adenomas (adenomatous polyp $\geq 1 \mathrm{~cm}$ or containing $>25 \%$ villous component or high-grade dysplasia). A recent review evaluated the results of CRC screening programs in Europe; for a positive FIT, the reported positive predictive value for advanced adenomas ranged from $5 \%$ in Ireland to $30 \%$ in Italy [5]. However, serrated polyps $\geq$ $1 \mathrm{~cm}$ are poorly detected as are all other screen-relevant lesions in the proximal colon [5]. Most recently, advances in technology have brought new non-invasive options; these include the multi-target stool DNA (MT-sDNA) (Cologuard®, Exact Sciences Corporation, Madison, WI) test and the methylated SEPTIN9 (SEPT9) blood plasma test (Epi proColon®, Epigenomics, San Diego, CA). MT-sDNA detects curablestage CRC with high sensitivity $93 \%$ (95\% CI, 84-98\%) to $100 \%(69-100 \%)$ and outperforms FIT in the detection of both advanced adenomas and serrated precursors with sensitivity increasing in association with risk of progression to cancer [17-19]. SEPT9 sensitivity for CRC appeared high in case-control studies but showed lesser performance in asymptomatic screening patients, in whom precursor sensitivity was less than historically seen with FIT [20]. With few studies directly comparing these non-invasive CRC screening options and no randomized controlled trial data on effectiveness, we sought to critically assess the available comparative literature on these tests. We further review indirect projections of test efficacy to guide clinicians caring for patients seeking an alternative to screening colonoscopy.
Overview of Stool-Based CRC Screening Tests

While there are multiple commercially available products, stool testing broadly falls into three platforms: gFOBT, FIT, and MT-sDNA (Table 1). None of these options requires a cathartic bowel-prep or anesthesia and is conducted at home. Both gFOBT and FIT require annual evaluation; MT-sDNA is recommended for every 3 -year use by the manufacturer and is

Table 1 Characteristics of commercially available non-invasive tests for CRC screening

\begin{tabular}{|c|c|c|c|}
\hline Test & Frequency & Evidence of efficacy & Other factors \\
\hline $\begin{array}{l}\text { Stool-based } \\
\text { gFOBT }\end{array}$ & $\begin{array}{l}\text { Every } \\
1 \text { year }\end{array}$ & $\begin{array}{l}\text {-Randomized controlled } \\
\text { trials show reduction } \\
\text { in mortality by } 14 \%\end{array}$ & $\begin{array}{l}\text { - Requires dietary and } \\
\text { medication } \\
\text { restrictions } \\
\cdot 3 \text { separate at-home } \\
\text { collections }\end{array}$ \\
\hline FIT & $\begin{array}{l}\text { Every } \\
1 \text { year }\end{array}$ & $\begin{array}{l}\text {-Cross-sectional studies } \\
\text { show higher } \\
\text { sensitivity that } \\
\text { gFOBT } \\
\text {-Modeling studies show } \\
\text { comparable benefits } \\
\text { and lower harms } \\
\text { compared to } \\
\text { colonoscopy } \\
\text {-Less sensitive for } \\
\text { lesions in the right } \\
\text { colon }^{\dagger}\end{array}$ & $\begin{array}{l}\text {-Single specimen } \\
\text { collected at home } \\
\text {-Adherence benefits } \\
\text { from patient } \\
\text { navigation (at } \\
\text { provider cost) }\end{array}$ \\
\hline MT-sDNA & $\begin{array}{c}\text { Every } 3 \\
\text { years }^{\dagger \dagger}\end{array}$ & $\begin{array}{l}\text {-Direct cross-sectional } \\
\text { comparison studies } \\
\text { show superiority to } \\
\text { FIT for curable-stage } \\
\text { CRC, advanced } \\
\text { adenoma, and } \\
\text { advanced sessile } \\
\text { serrated polyps } \\
\text {-Equally sensitive for } \\
\text { lesions in the right and } \\
\text { left colon } \\
\text {-Modeling studies show } \\
\text { comparable benefits } \\
\text { and harms to FIT }\end{array}$ & $\begin{array}{l}\text {-Single specimen } \\
\text { collected at home } \\
\text {-Patient navigation } \\
\text { included } \\
\text {-Diagnostic } \\
\text { colonoscopy is } \\
\text { sufficient to } \\
\text { evaluate all positive } \\
\text { results } \\
\text {-Specificity } \\
\text { comparable to FIT } \\
\text { performed for } \\
3 \text { years }\end{array}$ \\
\hline $\begin{array}{c}\text { Blood-based } \\
\text { SEPTIN9 }\end{array}$ & $\begin{array}{l}\text { Not } \\
\text { establis- } \\
\text { hed }\end{array}$ & $\begin{array}{l}\text {-Direct comparison } \\
\text { shows significantly } \\
\text { lower specificity than } \\
\text { FIT for CRC } \\
\text {-Direct comparison } \\
\text { shows lower } \\
\text { sensitivity for CRC } \\
\text { and precursors vs. } \\
\text { MT-sDNA }\end{array}$ & $\begin{array}{l}\text {-Assayed from blood } \\
\text { plasma; collection } \\
\text { cannot be done at } \\
\text { home } \\
\text {-Not endorsed by } \\
\text { guidelines* } \\
\text {-Limited insurance } \\
\text { coverage }\end{array}$ \\
\hline
\end{tabular}

\footnotetext{
${ }^{\dagger}$ Defined as proximal (right) or distal (left) to the splenic flexure

$\dagger$ Manufacturer recommendation

*Guaiac-based fecal occult blood test ( $g F O B T)$, fecal immunochemical test $(F I T)$, and multi-target stool DNA (MT-SDNA) are all endorsed by the United States Preventive Services Task Force (2016), Multi-Society Task Force on Colorectal Cancer Screening (2017), and American Cancer Society (2015)
} 
also supported by an Archimedes model (Archimedes Inc., San Francisco, CA) study that used a 200,000 patient population and found a reduction in CRC incidence and mortality by $57 \%$ and $67 \%$ respectively at 3-year interval testing [21]. Additionally, a $>2400$ person observational study of the positive and negative predictive values of MT-sDNA at 3-year intervals has now closed to enrollment (ClinicalTrials.gov Identifier: NCT02419716).

Peroxidase substances in fruits and vegetables and dietary heme will cross-react with the gFOBT assay; these must not be consumed for at least 3 days prior to the start of collection of three separate individual stool samples. FIT does not require dietary modification and utilizes a single stool sample. As reviewed below, FIT is also substantially more accurate than gFOBT and has largely replaced the use of gFOBT in clinical practice. FIT has many different manufacturers, each with slightly different assay performance characteristics. This is particularly attractive in countries with limited capability to perform colonoscopy [5]. No consensus for optimal threshold of hemoglobin detection by FIT has been determined. A threshold between 20 and $30 \mu \mathrm{g} / \mathrm{g}$ has been proposed for most countries whose colonoscopy capability can meet the anticipated 5\% positivity rate for FIT at this threshold [22]. The American Society for Gastrointestinal Endoscopy consensus statement on FIT favors a lower threshold cut-off to define a positive test, $\leq 20 \mu \mathrm{g} / \mathrm{g}$, and reports an expected test performance of $80 \%$ sensitivity for CRC and 20-30\% sensitivity for advanced neoplasia detection [23••]. A more recent systematic review explored the influence of different hemoglobin level thresholds to generate positive or negative calls on FIT performance [24••]. In their review, Imperiale et al. examined various thresholds spanning from $\leq 10$ to $\geq 20 \mu \mathrm{g} / \mathrm{g}$ and found the greatest sensitivity to be at a threshold of $10 \mu \mathrm{g} / \mathrm{g}$. At this level of detection, CRC sensitivity was 91\% (84-95\%). Advanced adenoma detection by the FIT assays overall ranged from $25 \%(20-31 \%)$ to $40 \%$ (33-47\%). Importantly, at a positive testing threshold between 10 and $20 \mu \mathrm{g} / \mathrm{g}$, a $7 \%$ false positive rate is expected [24••]. While FIT performance characteristics have usually been reported from clinical trials using colonoscopy as the criterion standard, this design is not always followed. In study settings where cost is a major constraint and FIT widely adopted in clinical practice, the positive predictive value of FIT has been measured by performing colonoscopy only on those with positive FIT; FIT-negative patients were followed with clinical registries to estimate unmeasured performance characteristics. Unfortunately, this approach has recently been shown to overestimate FIT performance due to potential bias in the modeling calculations used to report sensitivity and specificity and most notably overestimates sensitivity [25••].

Like FIT, MT-sDNA does not require modification of diet prior to use and assays one stool collection. While all three stool-based strategies measure occult blood, MT-sDNA also quantifies DNA targets exfoliated from CRC and precursors [26]. These DNA components include methylated BMP3 and $N D R G 4$ and mutant KRAS; ACTB is assayed to account for human DNA content in each sample, and results are reported as positive or negative based on a composite score generated by a validated, multi-parameter algorithm [27].

\section{FIT and MT-sDNA: Comparative Accuracy}

While the performance of FIT has been compared to colonoscopy in many studies, as reviewed above, there are only three studies that have directly compared FIT to MT-sDNA and colonoscopy (Table 2) [17-19]. These are critically important as this is the only way to assess the relative performance of these two commonly used stool tests. In the only study sufficiently powered to show a difference in CRC sensitivity ("DeeP-C" ClinicalTrials.gov number, NCT01397747), MTsDNA was superior to FIT for detection of any CRC or curable-stage CRC with a reported sensitivity of $92 \%$ (83$98 \%$ ) to $93 \%$ (84-97\%). To detect one colorectal cancer, 166 people would need to undergo screening with MTsDNA whereas 208 people would be required to undergo FIT [17••]. In all 3 studies, MT-sDNA showed significantly higher sensitivity for advanced pre-cancerous lesions. MTsDNA is also more sensitive for advanced sessile serrated polyps [17, 19]. With colonoscopy as the criterion standard, the sensitivity for detecting advanced precursors with MTsDNA was found to range between $41 \%(30-53 \%)$ and $48 \%$ $(37-59 \%)$ [18, 19]. In comparison, the reported sensitivity for advanced pre-cancers by FIT in these series was $22 \%$ (14 $33 \%)$ to $33 \%(23-43 \%)[18,19]$. When serrated lesions were considered separately, sensitivity for lesions $\geq 1 \mathrm{~cm}$ was $38 \%$ (16-64\%) to $42 \%(33-53 \%)$ for MT-sDNA and 5\% (2-12\%) to $7 \%(1-26 \%)$ for FIT $[17,19]$. MT-sDNA sensitivity is associated with size and advancing histology such that $63 \%$ (35-85\%) of lesions $\geq 2 \mathrm{~cm}, 75 \%$ (19-99\%) of lesions $\geq 3 \mathrm{~cm}$, and $69 \%$ of lesions with high-grade dysplasia were detected [18••].

All 3 studies used a cross-sectional design; in each, a single FIT measurement was more specific (93\% (91-95\%) to $95 \%$ (94-95\%)) than a single MT-sDNA test $(87 \%(86-87 \%)$ to 91\% (88-93\%)) [17-19]. This difference initially raised concerns that MT-sDNA would lead to additional risks by increasing the rate of unnecessary colonoscopies. Whereas FIT requires annual measurement, MT-sDNA is measured every 3 years. Thus, the nominal false positive rate of $5 \%$ generated by each round of FIT screening is compounded over 3 years to $15 \%$ but MT-sDNA false positives remain at $13 \%$. There is now some consensus that the specificity of FIT and MTsDNA is likely to be similar over a 3-year period of programmatic test use [28••]. It is important to note that specificity was calculated for FDA labeling by defining a stool test-negative 
result from colonoscopies at which either non-advanced adenomas, hyperplastic polyps, non-neoplastic diseases, or no pathology was found; for both MT-sDNA and FIT, specificity is higher when calculated from colonoscopies which were negative for any of those findings (Table 2). It is further anticipated from a recent report that a second-generation MT-sDNA test will demonstrate even stronger specificity at $92 \%$ (88-94\%) even when calculated from colonoscopies lacking only advanced neoplasia [29].

\section{Patients with False Positive Stool Screening Tests}

New data have also emerged to guide clinicians on the management of patients with false positive stool tests. Currently, no diagnostic follow-up is recommended after false positive FIT on the basis of low diagnostic yield and high cost [30-32]. What about MT-sDNA? Does the DNA component of this stool test imply greater risk for subsequent aerodigestive tract (gastrointestinal, pulmonary, or head/neck) cancers in the future? In the past year, Berger and colleagues released a long-term follow-up study of patients with negative colonoscopy; over 200 patients had positive MT-sDNA results and over 1000 were negative. All were enrolled during the DeeP-C study and thus were all at average CRC risk. After a median of 5.3 years of follow-up, there were 5 aerodigestive cancers in the false positive group and 11 cancers in the true negative group $(P=0.15)$ [33••]. These findings corroborate recommendations by the Multisociety Task Force in their 2017 CRC screening guidelines to avoid further testing in patients with MT-sDNA followed by negative high-quality diagnostic colonoscopy [28••].

\section{Stool Testing Influences Diagnostic Colonoscopy Yield}

Post-market studies demonstrate the high sensitivity of MTsDNA for advanced pre-cancers, even among those who had undergone prior screening colonoscopy, and have also demonstrated particularly high yield in the detection of proximal lesions $[34,35]$. This is of particular importance given that most interval colorectal neoplasia is right sided [36]. FIT sensitivity for advanced adenomas [37•] and cancers [17••] is biased toward the detection of left-sided lesions.

Both FIT and MT-sDNA testing also appear to influence the behavior of the physician at the time of diagnostic colonoscopy. Adenoma detection is significantly higher after a positive FIT in comparison to a similar group of patients undergoing screening colonoscopy alone [38 ${ }^{\bullet}$. This trend has also been demonstrated after a positive MT-sDNA with a particular increase in detection of lesions in the proximal 
colon and substantially longer withdrawal times [39・•]. Emerging data also suggest that MT-sDNA improves the detection of serrated polyps at diagnostic colonoscopy [40], an endpoint which was not shown after positive FIT [38•].

\section{Comparative Effectiveness by Computer Modeling}

The United States Preventive Services Task Force (USPSTF) has endorsed several methods for CRC screening; hierarchy among screening strategies was not used in the 2016 guideline update $\left[10^{\bullet} \cdot\right.$. The guideline statements aimed to portray an overall balance of the relative benefits and harms to screening and were predominantly based on modeling studies. Modeling is particularly useful as there are few randomized trials with mortality or incidence endpoints; these endpoints have not been measured for all screening options, and it is impractical (if not impossible) to directly measure benefits and harms over a person's lifetime.

For these estimates, the USPSTF commissioned a study using 3 validated microsimulation modeling platforms (Simulation Model of CRC, Microsimulation Screening Analysis for CRC, and CRC Simulated Population Model for Incidence and Natural History) [10, 41]. The primary measures of benefit were life-years gained and CRC deaths averted in comparison to no screening. Harms included (1) the anticipated number of gastrointestinal or cardiovascular complications attributable to colonoscopy, either for screening or in diagnostic follow-up of stool-based strategies, and (2) the total number of anticipated colonoscopies required for evaluation of positive stool-based strategies [41•]. Each model simulated the natural history of CRC based on the adenomacarcinoma sequence and outcome is influenced by the respective sensitivity and specificity for the screening test used (derived from single test performance) [41•]. The greatest gain in life-years was with colonoscopy screening every 10 years; however, the gains over those achieved by non-invasive testing were surprisingly slim [41•]. Life-years gained through annual FIT were estimated to be $90 \%$ of those gained by colonoscopy and MT-sDNA life-years gained were roughly $93 \%$ of those obtained by annual FIT [10••]. Harms from either non-invasive strategy were substantially lower than those attributed to colonoscopy. The number of diagnostic colonoscopies required for the MT-sDNA strategy (1827) was fewer than that anticipated for the FIT strategy (1899), confirming the programmatic similarity in specificity from MT-sDNA, compared to FIT [10], as reviewed (above).

It is important to note that the models excluded the serrated polyp pathway that accounts for a third of CRC [42] and did not account for sensitivity variation based on polyp location [41 •]. The models also used performance estimates for colonoscopy that assumed colonoscopy sensitivity based on tandem colonoscopy by expert operators that may be higher than suggested by recent studies showing high rates of variability among individual providers [43]. While imperfect, these methods have provided valuable insight into how these tests may perform. Plainly stated, MT-sDNA and FIT show highly comparable efficacy relative to colonoscopy under optimal colonoscopy conditions and with perfect test adherence.

\section{FIT and MT-sDNA Adherence}

In the real world, adherence either to colonoscopy or noninvasive CRC screening is imperfect. Outside the USA, FIT is the dominant option used for population-wide CRC screening. The relatively high upfront price of MT-sDNA (approximately \$500) and colonoscopy relative to FIT is a major adoption barrier. However, less than $50 \%$ of patients who have a FIT ordered will subsequently complete the test on the first round and adherence diminishes with each annual interval [44••]. Providers and systems that use FIT for CRC screening have improved adherence by providing patient support programs, at substantial cost; this is estimated to be over $\$ 150$ per testing cycle in the USA [45]. How do these indirect costs and imperfect adherence rates impact cost-effectiveness? A Markov model of average-risk CRC screening was used to compare variable participation and assess cost-effectiveness of screening with MT-sDNA versus FIT or colonoscopy [45]. While all 3 options are cost-effective relative to no screening, colonoscopy and FIT are the dominant strategies, in this model, assuming perfect adherence. However, MTsDNA becomes the dominant strategy if test adherence is 1.7-fold higher than FIT. Real-world manufacturer data show an overall $68 \%$ adherence with MT-sDNA, which may be as high as $71 \%$ in Medicare beneficiaries [46]. Up to $40 \%$ of patients using MT-sDNA testing have reported participation in screening for the first time and a substantial number of these appear to be overdue to initiate screening by 10 years or more [35*0]. This favorable rate of intent-to-screen participation may be a result of a manufacturer-provided compliance program available to all patients for whom MT-sDNA has been ordered at no additional cost to patient or provider [46].

\section{Plasma-Based Colorectal Cancer Screening}

While MT-sDNA testing appears highly acceptable to an increasing number of patients, screening for CRC with a blood sample may be a more attractive option for some. For this approach to be effective, it must show significantly greater adherence and exceed the current performance bar set by stool-based testing by either FIT or MT-sDNA for both $\mathrm{CRC}$ and precursors. As of early 2020 , only one blood plasma test, methylated SEPT9, has been approved by the FDA. Prior 
to clinical availability of either test, prototypes of MT-sDNA and SEPT9 tests were run in blinded fashion on matched stool and blood samples from $30 \mathrm{CRC}$ cases, 22 advanced pre-cancers, 49 plasma controls, and 46 colonoscopy-negative stool controls. SEPT9 detected $60 \%$ of CRCs, detected $14 \%$ of precancers, and was positive in $27 \%$ controls. In contrast, MTsDNA was positive in $87 \%$ CRCs, was positive in $82 \%$ of precursors, and had only a $7 \%$ false positive rate [47]. In the screening-setting study leading to FDA approval, methylated SEPT9 test was performed on 7941 patients prior to blinded colonoscopy; there was no comparison to stool testing. Across all stages of CRC, SEPT9 was $48 \%$ sensitive and almost $92 \%$ specific but detected only $11 \%$ of advanced pre-cancers [20]. When reviewed by USPSTF, the Task Force expressed concern that SEPT9 was not likely to be comparably effective to other options due to low sensitivity for CRCs and precursors [20]. In a more recent study that mixed referred cases and a prospective screening arm, a re-configured SEPT9 test was non-inferior to FIT for CRC sensitivity ( $72 \%$ and $68 \%$, respectively) but at substantially lower specificity (97\% and $81 \%$, respectively) [48].

Several alternative blood-based assays are in development to advance non-invasive CRC screening via a "liquid biopsy." For example, Colvera ${ }^{\circledR}$ by ClinicalGenomics (Bridgewater, $\mathrm{NJ}$ ) is a plasma test of methylated DNA that is designed for surveillance after treatment of CRC; it is being evaluated for CRC screening but the adenoma sensitivity is 9\% [49•]. Cellfree DNA coupled with machine learning is also being investigated but is currently demonstrating detection only after the development CRC [50 ]. CancerSEEK $®$ by Thrive Earlier Detection Corp. (Cambridge, MA) aims to increase early cancer detection through utilization of protein biomarkers in addition to tumor genetic alterations [51•]. CancerSEEK ${ }^{\circledR}$ is also being designed to detect several different cancer types via a single blood sample. When evaluated among 1005 patients diagnosed with stage I to III ovary, liver, stomach, pancreas, esophagus, colorectal, lung, or breast cancer, the median sensitivity for stage I cancers combined was 43\% [51•]. Replication of these results has not yet been reported. More recently, an analysis from the Circulating Cell-free Genome Atlas (CCGA) study (NCT02889978) sponsored by GRAIL (Menlo Park, CA) also reported on sensitivity for plasmabased detection of early cancers, including CRC, where sensitivity was greater than $50 \%$ for stage I and greater than $75 \%$ for stages II-III [52].

Despite these promising results, it is critical to highlight that there is no blood sample test available at this time with prospectively validated sensitivity for advanced adenomas equivalent to either FIT or MT-sDNA in the screening setting. We hypothesize that plasma-based detection of pre-cancers is likely to remain sub-optimal on the basis of biological factors rather than assay sensitivity or marker optimization. Precursors to CRC develop among epithelial cells confined to the colonic mucosa. By definition, these lesions lack a direct blood supply, as vessels are submucosal structures and not in direct cellular approximation to colorectal neoplasia until invasive cancer occurs (Fig. 1) [53]. In contrast, exfoliation of neoplastic cells and cellular debris into the luminal mucocellular layer has been shown to be continuous and abundant from both CRC and precursor lesions [26]. Without detection of advanced precursors equivalent to or superior to stool-based tests, plasma tests are not anticipated to be effective in reducing CRC incidence.

\section{Conclusion and Future Directions}

Widespread screening for CRC has reduced incidence and mortality of this devastating disease but remains short of public health goals [11]. The relatively recent expansion of noninvasive strategies for screening will not eliminate the need for colonoscopy but may increase population participation in screening [14]. Encouragingly, several studies have also suggested a potential for added benefit by the utilization of noninvasive tests for screening in that diagnostic colonoscopy may be performed with higher quality when physicians are aware of the positive stool test result $[38 \bullet, 39 \bullet \cdot]$. Observed increases in adenoma detection at colonoscopy [54] after stool testing and advanced adenomas detected by MT-sDNA after negative colonoscopy [40] are both anticipated to reduce the rate of post-colonoscopy interval CRC [43], particularly in the proximal colon. These emerging concepts, and the use of interval CRC as a clinically impactful endpoint, appear highly deserving of prospective evaluation.

\section{Compliance with Ethical Standards}

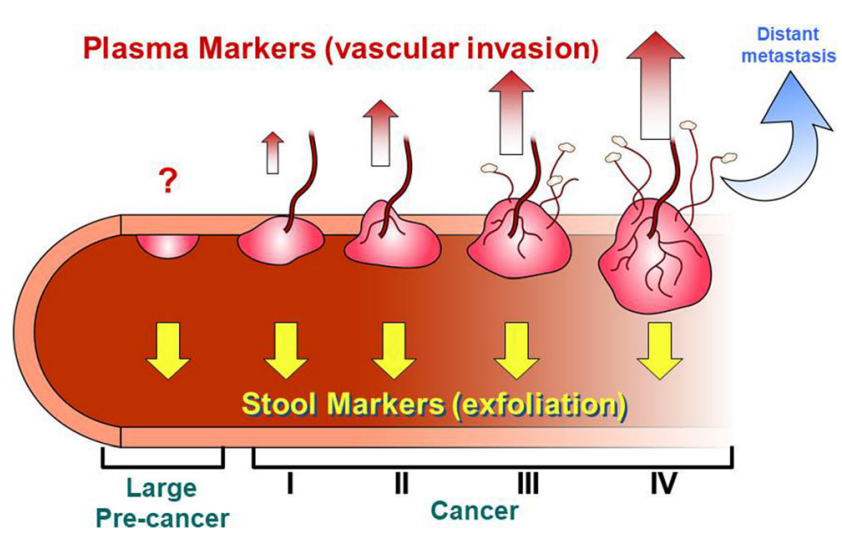

Fig. 1 Conceptual model in progression of colorectal tumor marker generation and subsequent detection through stool exfoliation versus vascular invasion and subsequent plasma detection. Adapted with permission. Ahlquist DA, Taylor WR, Mahoney DW, Zou H, Domanico M, Thibodeau SN, et al. The stool DNA test is more accurate than the plasma septin 9 test in detecting colorectal neoplasia. Clin Gastroenterol Hepatol. 2012;10(3):272-7.e1 
Conflict of Interest Dr. Ebner has no potential conflicts to disclose. Dr. Kisiel is listed as an inventor on joint intellectual property of Mayo Clinic and Exact Sciences (Madison, WI) and may receive royalties in accordance with Mayo Clinic policy.

Human and Animal Rights and Informed Consent All reported studies/ experiments with human or animal subjects performed by the authors have been previously published and complied with all applicable ethical standards (including the Helsinki declaration and its amendments, institutional/national research committee standards, and international/national/institutional guidelines).

Open Access This article is licensed under a Creative Commons Attribution 4.0 International License, which permits use, sharing, adaptation, distribution and reproduction in any medium or format, as long as you give appropriate credit to the original author(s) and the source, provide a link to the Creative Commons licence, and indicate if changes were made. The images or other third party material in this article are included in the article's Creative Commons licence, unless indicated otherwise in a credit line to the material. If material is not included in the article's Creative Commons licence and your intended use is not permitted by statutory regulation or exceeds the permitted use, you will need to obtain permission directly from the copyright holder. To view a copy of this licence, visit http://creativecommons.org/licenses/by/4.0/.

\section{References}

Papers of particular interest, published recently, have been highlighted as:

- Of importance

•. Of major importance

1. Society AC. Cancer Facts \& Figures 2020. American Cancer Society: Atlanta; 2020.

2. Yang DX, Gross CP, Soulos PR, Yu JB. Estimating the magnitude of colorectal cancers prevented during the era of screening: 1976 to 2009. Cancer. 2014;120(18):2893-901. https://doi.org/10.1002/ cncr.28794.

3. Levin TR, Corley DA, Jensen CD, Schottinger JE, Quinn VP, Zauber AG, et al. Effects of Organized Colorectal Cancer Screening on Cancer Incidence and Mortality in a Large Community-Based Population. Gastroenterology. 2018;155(5): 1383-91.e5. https://doi.org/10.1053/j.gastro.2018.07.017.

4. Keum N, Giovannucci E. Global burden of colorectal cancer: emerging trends, risk factors and prevention strategies. Nat Rev Gastroenterol Hepatol. 2019;16(12):713-32. https://doi.org/10. 1038/s41575-019-0189-8.

5. Navarro M, Nicolas A, Ferrandez A, Lanas A. Colorectal cancer population screening programs worldwide in 2016: An update. World J Gastroenterol. 2017;23(20):3632-42. https://doi.org/10. 3748/wjg.v23.i20.3632.

6. Winawer SJ, Zauber AG, Ho MN, O'Brien MJ, Gottlieb LS, Sternberg SS, et al. Prevention of Colorectal Cancer by Colonoscopic Polypectomy. N Engl J Med. 1993;329(27):197781. https://doi.org/10.1056/nejm199312303292701.

7. Atkin WS, Edwards R, Kralj-Hans I, Wooldrage K, Hart AR, Northover JM, et al. Once-only flexible sigmoidoscopy screening in prevention of colorectal cancer: a multicentre randomised controlled trial. Lancet. 2010;375(9726):1624-33. https://doi.org/10. 1016/s0140-6736(10)60551-x.
8. Nishihara R, Wu K, Lochhead P, Morikawa T, Liao X, Qian ZR, et al. Long-term colorectal-cancer incidence and mortality after lower endoscopy. N Engl J Med. 2013;369(12):1095-105. https:// doi.org/10.1056/NEJMoa1301969.

9. Gupta AK, Melton LJ 3rd, Petersen GM, Timmons LJ, Vege SS, Harmsen WS, et al. Changing trends in the incidence, stage, survival, and screen-detection of colorectal cancer: a population-based study. Clin Gastroenterol Hepatol. 2005;3(2):150-8. https://doi. org/10.1016/s1542-3565(04)00664-0.

10.• Bibbins-Domingo K, Grossman DC, Curry SJ, Davidson KW, Epling JW Jr, Garcia FAR, et al. Screening for Colorectal Cancer: US Preventive Services Task Force Recommendation Statement. JAMA. 2016;315(23):2564-75. https://doi.org/10.1001/jama. 2016.5989 This guideline reviews the supporting literature and modeling used to inform the US Preventive Services Task Force guideline recommendations on colorectal cancer screening.

11. Klabunde CNJD, King JB, White A, Plescia M. Vital Signs: Colorectal Cancer Screening Test Use-United States. CDC Morbidity and Mortality Weekly Report. 2012;2013(62):881-8.

12. Schroy PC 3rd, Lal S, Glick JT, Robinson PA, Zamor P, Heeren TC. Patient preferences for colorectal cancer screening: how does stool DNA testing fare? Am J Manag Care. 2007;13(7):393-400.

13. Denberg TD, Melhado TV, Coombes JM, Beaty BL, Berman K, Byers TE, et al. Predictors of nonadherence to screening colonoscopy. J Gen Intern Med. 2005;20(11):989-95. https://doi.org/10. 1111/j.1525-1497.2005.00164.x.

14. Inadomi JM, Vijan S, Janz NK, Fagerlin A, Thomas JP, Lin YV, et al. Adherence to colorectal cancer screening: a randomized clinical trial of competing strategies. Arch Intern Med. 2012;172(7): 575-82. https://doi.org/10.1001/archinternmed.2012.332.

15. Mandel JS, Bond JH, Church TR, Snover DC, Bradley GM, Schuman LM, et al. Reducing Mortality from Colorectal Cancer by Screening for Fecal Occult Blood. N Engl J Med. 1993;328(19): 1365-71. https://doi.org/10.1056/nejm199305133281901.

16. Heresbach D, Manfredi S, D'Halluin PN, Bretagne JF, Branger B. Review in depth and meta-analysis of controlled trials on colorectal cancer screening by faecal occult blood test. Eur J Gastroenterol Hepatol. 2006;18(4):427-33. https://doi.org/10.1097/00042737200604000-00018.

17.• Imperiale TF, Ransohoff DF, Itzkowitz SH, Levin TR, Lavin P, Lidgard GP, et al. Multitarget stool DNA testing for colorectalcancer screening. N Engl J Med. 2014;370(14):1287-97. https:// doi.org/10.1056/NEJMoa1311194 This prospective crosssectional study of MT-sDNA and FIT against colonoscopy in almost 10,000 average risk patients was pivotal evidence for FDA approval of MT-sDNA.

18.• Redwood DG, Asay ED, Blake ID, Sacco PE, Christensen CM, Sacco FD, et al. Stool DNA Testing for Screening Detection of Colorectal Neoplasia in Alaska Native People. Mayo Clin Proc. 2016;91(1):61-70. https://doi.org/10.1016/j.mayocp.2015.10.008 This prospective screening-setting study of MT-sDNA performance in an Alaska Native population was the 2nd study to showed improved sensitivity for screen relevant neoplasia utilizing MT-sDNA compared with FIT and was crucial to adoption of MT-sDNA.

19.•• Bosch LJW, Melotte V, Mongera S, Daenen KLJ, Coupe VMH, van Turenhout ST, et al. Multitarget Stool DNA Test Performance in an Average-Risk Colorectal Cancer Screening Population. Am J Gastroenterol. 2019;114(12):1909-18. https://doi.org/10.14309/ ajg.0000000000000445 This is only the 3rd direct comparison of MT-sDNA to FIT, but confirms that MT-sDNA had increased sensitivity for detecting advanced precancerous lesions.

20. Church TR, Wandell M, Lofton-Day C, Mongin SJ, Burger M, Payne SR, et al. Prospective evaluation of methylated SEPT9 in 
plasma for detection of asymptomatic colorectal cancer. Gut. 2014;63(2):317-25. https://doi.org/10.1136/gutjnl-2012-304149.

21. Berger BM, Schroy PC, Dinh TA. Screening for Colorectal Cancer Using a Multitarget Stool DNA Test: Modeling the Effect of the Intertest Interval on Clinical Effectiveness. Clin Colorectal Cancer. 2016;15(3):e65-74. https://doi.org/10.1016/j.clcc.2015.12.003.

22. Hamza S, Dancourt V, Lejeune C, Bidan JM, Lepage C, Faivre J. Diagnostic yield of a one sample immunochemical test at different cut-off values in an organised screening programme for colorectal cancer. Eur J Cancer. 2013;49(12):2727-33. https://doi.org/10. 1016/j.ejca.2013.03.023.

23.• Robertson DJ, Lee JK, Boland CR, Dominitz JA, Giardiello FM, Johnson DA, et al. Recommendations on Fecal Immunochemical Testing to Screen for Colorectal Neoplasia: A Consensus Statement by the US Multi-Society Task Force on Colorectal Cancer. Gastroenterology. 2017;152(5):1217-37.e3. https://doi.org/10. 1053/j.gastro.2016.08.053 Consensus report on FIT by the American Society for Gastrointestinal Endoscopy whose literature review built upon the prior reviews used for the US Preventive Services Task Force as well as a review centered on the sensitivity of FIT for CRC. The summary includes recommendation on FIT application such as the threshold level to define a positive FIT test, $20 \mu \mathrm{g} / \mathrm{g}$.

24.• Imperiale TF, Gruber RN, Stump TE, Emmett TW, Monahan PO. Performance Characteristics of Fecal Immunochemical Tests for Colorectal Cancer and Advanced Adenomatous Polyps: A Systematic Review and Meta-analysis. Ann Intern Med. 2019;170(5):319-29. https://doi.org/10.7326/m18-2390 High sensitivity and specificity for colorectal cancer is shown to be dependent upon the manufacturer recommended thresholds for positive test calls. Sensitivity of one-time testing for advanced adenoma is low, regardless of threshold.

25.• Brenner H, Gies A, Selby K. Overestimated Sensitivity of Fecal Immunochemical Tests in Screening Cohorts With RegistryBased Follow-up. Am J Gastroenterol. 2019;114(11):1795-801. https://doi.org/10.14309/ajg.0000000000000412 This analysis shows that registry-based studies in which indirect modeling was used to report sensitivity and specificity of colorectal cancer detection by fecal immunochemical testing, will significantly overestimate sensitivity in comparison to the use of colonoscopy as a criterion standard for all patients.

26. Ahlquist DA, Harrington JJ, Burgart LJ, Roche PC. Morphometric analysis of the "mucocellular layer" overlying colorectal cancer and normal mucosa: relevance to exfoliation and stool screening. Hum Pathol. 2000;31(1):51-7. https://doi.org/10.1016/s0046-8177(00) 80198-7.

27. Lidgard GP, Domanico MJ, Bruinsma JJ, Light J, Gagrat ZD, Oldham-Haltom RL, et al. Clinical performance of an automated stool DNA assay for detection of colorectal neoplasia. Clin Gastroenterol Hepatol. 2013;11(10):1313-8. https://doi.org/10. 1016/j.cgh.2013.04.023

28.• Rex DK, Boland CR, Dominitz JA, Giardiello FM, Johnson DA, Kaltenbach T, et al. Colorectal Cancer Screening: Recommendations for Physicians and Patients From the U.S. Multi-Society Task Force on Colorectal Cancer. Gastroenterology. 2017;153(1):307-23. https://doi.org/10.1053/j. gastro.2017.05.013 The specificity of once every 3-year testing with MT-sDNA is approximately equal to FIT specificity over 3 annual rounds of testing.

29. Domanico M, Kisiel J, Gagrat Z, Bourne B, Allawi H, Taylor W, et al. Novel Multi-Target Stool DNA Marker Panel Yields Highly Accurate Detection of Colorectal Cancer and Premalignant Neoplasia: 325. Am J Gastroenterol. 2019;114:S191. https://doi. org/10.14309/01.ajg.0000590832.76462.30.

30. Hubbard RA, Johnson E, Hsia R, Rutter CM. The cumulative risk of false-positive fecal occult blood test after 10 years of colorectal cancer screening. Cancer Epidemiol Biomark Prev. 2013;22(9): 1612-9. https://doi.org/10.1158/1055-9965.Epi-13-0254.

31. Allard J, Cosby R, Del Giudice ME, Irvine EJ, Morgan D, Tinmouth J. Gastroscopy following a positive fecal occult blood test and negative colonoscopy: systematic review and guideline. Canadian J Gastroenterol. 2010;24(2):113-20. https://doi.org/10. 1155/2010/516363.

32. Frazier AL, Colditz GA, Fuchs CS, Kuntz KM. Cost-effectiveness of screening for colorectal cancer in the general population. JAMA. 2000;284(15):1954-61. https://doi.org/10.1001/jama.284.15.1954.

33.• Berger BM, Kisiel JB, Imperiale TF, Geenen DJ, Heigh RI, Mahoney DW, et al. Low Incidence of Aerodigestive Cancers in Patients With Negative Results From Colonoscopies, Regardless of Findings From Multitarget Stool DNA Tests. Clin Gastroenterol Hepatol. 2019. https://doi.org/10.1016/j.cgh.2019.07.057 Low incidence of aerodigestive cancer was found through retrospective cohort review of patients that had been enrolled during the DeeP-C landmark study who had a positive MTsDNA test and negative diagnostic colonoscopy. This supports guideline recommendations that no further diagnostic evaluation is required for apparently false positive MT-sDNA in asymptomatic patients after high-quality diagnostic colonoscopy.

34. Eckmann JD, Ebner DW, Kisiel JB. Multi-Target Stool DNA Testing for Colorectal Cancer Screening: Emerging Learning on Real-world Performance. Current Treatment Options Gastroenterol 2020. doi:https://doi.org/10.1007/s11938-02000271-5.

35.• Eckmann JD, Ebner DW, Bering J, Kahn A, Rodriguez E, Devens ME, et al. Multitarget Stool DNA Screening in Clinical Practice: High Positive Predictive Value for Colorectal Neoplasia Regardless of Exposure to Previous Colonoscopy. Am J Gastroenterol. 2020. https://doi.org/10.14309/ajg.0000000000000546 This largest post-market evaluation of MT-sDNA at a multi-center academic practice included patients who had previously undergone screening colonoscopy and those who had not. Positive predictive value for colorectal neoplasia is preserved regardless of prior colonoscopy for colon cancer screening.

36. Corley DA, Jensen CD, Marks AR, Zhao WK, Lee JK, Doubeni CA, et al. Adenoma Detection Rate and Risk of Colorectal Cancer and Death. N Engl J Med. 2014;370(14):1298-306. https://doi.org/ 10.1056/NEJMoa1309086.

37.• Brenner H, Niedermaier T, Chen H. Strong subsite-specific variation in detecting advanced adenomas by fecal immunochemical testing for hemoglobin. Int J Cancer. 2017;140(9):2015-22. https://doi.org/10.1002/ijc.30629 FIT performance for proximal advanced adenomas is substantially lower than left-sided lesions.

38. Kligman E, Li W, Eckert GJ, Kahi C. Adenoma Detection Rate in Asymptomatic Patients with Positive Fecal Immunochemical Tests. Dig Dis Sci. 2018;63(5):1167-72. https://doi.org/10.1007/s10620018-4984-9. This retrospective evaluation of findings at time of diagnostic colonoscopy for a positive FIT showed that adenoma detection was greater than in screening colonoscopies; however there was no change in sessile serrated adenoma detection.

39.• Johnson DH, Kisiel JB, Burger KN, Mahoney DW, Devens ME, Ahlquist DA, et al. Multitarget stool DNA test: clinical performance and impact on yield and quality of colonoscopy for colorectal cancer screening. Gastrointest Endosc. 2017;85(3):657-65.e1. https:// doi.org/10.1016/j.gie.2016.11.012 Among providers evaluating patients with positive MT-sDNA tests, the same colonoscopists found more polyps and had longer withdrawal times when they were aware of, versus blinded to, the MT-sDNA result.

40. Ebner D, Eckmann J, Burger KN, Mahoney DW, Devens ME, Lowrie KL, et al. Sa1042 Multi-Target Stool Dna Testing Enriches Detection Of Colorectal Neoplasia By Colonoscopy But 
Yield Is Influenced By Baseline Polyp Detection Rates. Gastrointest Endosc. 2019;89(6, Supplement):AB149-AB50. https://doi.org/10.1016/j.gie.2019.03.060.

41. Knudsen AB, Zauber AG, Rutter CM, Naber SK, Doria-Rose VP, Pabiniak C, et al. Estimation of Benefits, Burden, and Harms of Colorectal Cancer Screening Strategies: Modeling Study for the US Preventive Services Task Force. JAMA. 2016;315(23):2595-609. https://doi.org/10.1001/jama.2016.6828 USPSTF commissioned these modeling analyses to estimate benefits and harms of various colon cancer screening modalities.

42. Snover DC. Update on the serrated pathway to colorectal carcinoma. Hum Pathol. 2011;42(1):1-10. https://doi.org/10.1016/j. humpath.2010.06.002.

43. Fayad NF, Kahi CJ. Colonoscopy Quality Assessment. Gastrointinal Endosc Clin. 2015;25(2):373-86. https://doi.org/10. 1016/j.giec.2014.11.008.

44.• Nielson CM, Vollmer WM, Petrik AF, Keast EM, Green BB, Coronado GD. Factors Affecting Adherence in a Pragmatic Trial of Annual Fecal Immunochemical Testing for Colorectal Cancer. J Gen Intern Med. 2019;34(6):978-85. https://doi.org/10.1007/ s11606-018-4820-0 This observational study showed FIT return rates and identified factors associated with FIT adherence over the study period. First and second year completion were $46 \%$ and $41 \%$ respectively.

45. Ladabaum U, Mannalithara A. Comparative Effectiveness and Cost Effectiveness of a Multitarget Stool DNA Test to Screen for Colorectal Neoplasia. Gastroenterology. 2016;151(3):427-39.e6. https://doi.org/10.1053/j.gastro.2016.06.003.

46. Corporation ES. Frequently asked questions. 2020.

47. Ahlquist DA, Taylor WR, Mahoney DW, Zou H, Domanico M, Thibodeau SN, et al. The stool DNA test is more accurate than the plasma septin 9 test in detecting colorectal neoplasia. Clin Gastroenterol Hepatol. 2012;10(3):272-7.e1. https://doi.org/10. 1016/j.cgh.2011.10.008.

48. Johnson DA, Barclay RL, Mergener K, Weiss G, König T, Beck J, et al. Plasma Septin9 versus fecal immunochemical testing for colorectal cancer screening: a prospective multicenter study. PLoS One. 2014;9(6):e98238-e. https://doi.org/10.1371/journal.pone. 0098238 .
49. Boulter N, Tevz G, Yu B, Chan M, Murray D, Symonds EL, et al. An improved method for detection of methylated circulating tumor DNA in colorectal cancer. J Clin Oncol. 2019;37(15 suppl): e15120-e. https://doi.org/10.1200/JCO.2019.37.15_suppl.e15120 Performance characteristics in detection of malignancy for an emerging plasma based test using methylated DNA.

50. Wan N, Weinberg D, Liu T-Y, Niehaus K, Ariazi EA, Delubac D, et al. Machine learning enables detection of early-stage colorectal cancer by whole-genome sequencing of plasma cell-free DNA. BMC Cancer. 2019;19(1):832. https://doi.org/10.1186/s12885019-6003-8 Emerging non-invasive blood based assay with machine learning demonstrates early-stage CRC detection.

51. Cohen JD, Li L, Wang Y, Thoburn C, Afsari B, Danilova L, et al. Detection and localization of surgically resectable cancers with a multi-analyte blood test. Science. 2018;359(6378):926-30. https:// doi.org/10.1126/science.aar3247 Performance characteristics of a novel blood test of mutations in cell-free DNA and tumor proteins show promise among a cohort of patients with stage I-III cancers, including CRC.

52. Liu MC, Jamshidi A, Venn O, Fields AP, Maher MC, Cann G, et al. Genome-wide cell-free DNA (cfDNA) methylation signatures and effect on tissue of origin (TOO) performance. J Clin Oncol. 2019;37(15_suppl):3049. https://doi.org/10.1200/JCO.2019.37. 15_suppl.3049.

53. Berger BM, Ahlquist DA. Stool DNA screening for colorectal neoplasia: biological and technical basis for high detection rates. Pathology. 2012;44(2):80-8. https://doi.org/10.1097/PAT. 0b013e3283502fdf.

54. Eckmann J, Ebner D, Bering J, Kahn A, Rodriguez EA, Mahoney DW, et al. Tu1015 - Multi-Target Stool Dna Testing: Yield As a Function of Time Since Last Colonoscopy. Gastroenterology. 2019;156(6, Supplement 1):S-947-S-8. https://doi.org/10.1016/ S0016-5085(19)39328-X.

Publisher's Note Springer Nature remains neutral with regard to jurisdictional claims in published maps and institutional affiliations. 